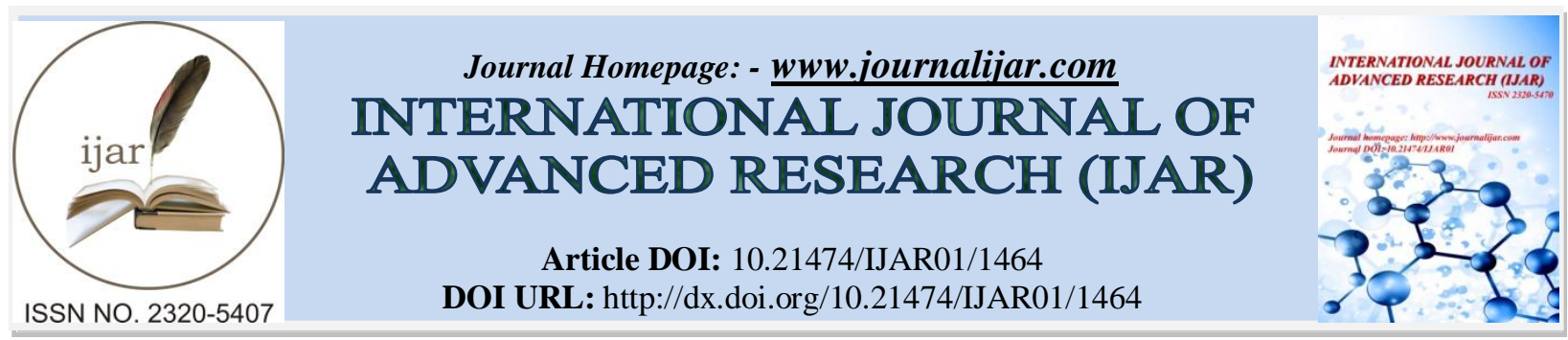

RESEARCH ARTICLE

\title{
EVALUATION OF THE POTENTIAL OF INTERLEUKIN-9 EXPRESSION AS A PROGNOSTIC FACTOR FOR CHRONIC LYMPHOCYTIC LEUKEMIA IN A COHORT OF EGYPTIAN PATIENTS
}

\author{
${ }^{*}$ Hadeer A Abbassy ${ }^{1}$, Reham A Aboelwafa ${ }^{1}$ and Omar M Ghallab ${ }^{2}$. \\ 1. Clinical pathology department, Faculty of Medicine, Alexandria University, Egypt. \\ 2. Clinical hematology department, Faculty of Medicine, Alexandria University, Egypt.
}

\section{Manuscript Info \\ Manuscript History \\ Received: 18 July 2016 \\ Final Accepted: 19 August 2016 \\ Published: September 2016}

Key words:-

\section{Abstract}

Chronic lymphocytic leukemia (CLL) is a common lymphoid malignancy that has a highly variable clinical course. Genomic features as zeta-chain-associated protein kinase 70 (ZAP70) expression and $\mathrm{CD} 38$ expression provide further differentiation of disease prognosis. Extensive studies have confirmed the oncogenic activities of IL-9 in lymphoma. The aim of the current study was to investigate the contribution of IL-9 expression to the pathogenesis of CLL and its correlation to other prognostic parameters. This study was conducted on 80 patients at diagnosis with CLL and 80 healthy controls. Using real time polymerase chain reaction and enzyme linked immunosorbant assay, IL-9 mRNA expression and its serum level were compared between patients and controls. They were both correlated with other prognostic factors. There was an overexpression of IL-9 in CLL patients that correlated with modified Rai staging, ZAP70, CD38 and all hallmarks of an active and aggressive disease. The correlation between IL-9 upregulation and patient characteristics provided direct clinical evidence for its contribution to the pathogenesis of CLL. In conclusion, significantly higher expression of IL -9 measured at both the mRNA and the protein levels in patients with CLL that correlates with a more complex course of the disease and worse prognosis may allow one to speculate its importance in the pathogenesis of the disease and its possible impact on prognosis.

Copy Right, IJAR, 2016,. All rights reserved.

\section{Introduction:-}

Chronic lymphocytic leukemia (CLL) has a highly unpredictable clinical course, ranging from rapid fatal progression to a relatively indolent behavior with normal life expectancy. It is characterized by the proliferation and progressive accumulation of mature B lymphocytes that express both the T-cell antigen CD5 and B cell surface antigens CD19, CD20, and CD23[1].

Genomic chacteristics such as mutational status of immunoglobulin heavy chain variable region genes (IGHV), TP53 tumor suppressor gene and ataxia telangiectasia mutated (ATM) gene, zeta-chain-associated protein kinase 70 (ZAP70) expression, $\beta 2$-microglobulin, interphase cytogenetics, and complex karyotype on metaphase cytogenetics, demonstrate further differentiation of disease prognosis [2]. Other prognostic markers include microRNA expression profiles [3], C-334 methylation status [4], CD38 antigen expression [5] and lipoprotein lipase (LPL) [6]. The most 
documented molecular predictor of disease progression is the presence or absence of somatic mutations in the (IGHV) region of leukemic cells of CLL [7]. CLL patients with unmutated IGHV genes have a greater risk of relapse after stem cell transplantation [8]. Additionally, unfavorable aberrations (11q-, 17p-) occur usually in IGHV-unmutated people, while favorable aberrations (13q single) are more encountered in the IGHV-mutated subgroup [9]. Because (IGHV) mutation analysis is not always available in routine clinical laboratories, other surrogate markers have become attractive as an indication of CLL status [7].

Interleukin (IL)-9 was initially characterized as a growth factor for T-cell lines, mast cell lines, and hematopoietic tumor cells [10]. In vivo, IL-9 is involved in asthma, in immune reactions against parasites, and in lymphoma development [11]. IL-9 is a member of the common $\gamma$-chain family of cytokines, using the $\gamma$-chain receptor together with the cytokine-specific receptor, IL-9 receptor (IL-9R) $\alpha$ [12]. The pro-proliferative and anti-apoptotic effect of IL-9 were basically dependent on its high-affinity binding with IL-9R. Receptor-ligand interaction in turn activates the Janus kinase-signal transducer and activator of transcription (JAK/STAT) pathway and consequently regulates its downstream apoptosis proteins [13].

It is a T-cell-derived lymphokine that triggers the proliferation of various lymphoid and hemopoietic cells [14]. A resurgence of interest in IL-9 has been spurred as a result of an expanded identification of its receptor on various immune cells [15]. The dysregulated expression of IL-9 can be detected in biopsies as well as serum from patients with CLL, Hodgkin's disease (HD), nasal natural killer (NK)/T-cell lymphoma as well as anaplastic large cell lymphomas (ALCL) [16].

The aim of the current study was to investigate the contribution of IL9 expression to the pathogenesis of chronic lymphocytic leukemia (CLL) and its correlation to other prognostic parameters.

\section{Material and methods:-}

This study was conducted on 80 patients at diagnosis with chronic lymphocytic leukemia (CLL). Patients, who met the diagnostic criteria for CLL, were selected from the outpatient clinic of Alexandria main university hospital between January 2014 and December 2015. The patients were 52 males and 28 females with age range from 42 to 72 years (median age 59.5). Eighty age and sex matched healthy volunteers were selected as a control group. They were 42 males and 38 females with age range from 40 to 70 years (median age 57.5). The selection of these patients was based on the following criteria: full history taking; thorough clinical examination; peripheral blood morphologies, immunophenotyping score $\geq 4$, and absolute lymphocyte count $\geq 5.0 \times 10^{9} / \mathrm{L}$. Clinical stage was determined using the modified Rai staging system. All patients were untreated and peripheral blood mononuclear cells (PBMCs) were isolated from EDTA blood.

The study was approved by the medical ethics committee and informed consents were obtained from all participants involved in the study. All procedures followed were in accordance with the ethical standards of the responsible committee on human experimentation (institutional and national) and with the Helsinki Declaration of 1975, as revised in 2008 (5).

\section{Cellular immunophenotypic analysis:-}

All flowcytometric analyses were carried out on a Becton Dickinson, FACSCalibur flowcytometer equipped with Cell Quest software (Becton Dickinson, San Diego, CA, USA). Whole blood was stained with the following mAbs, CD22-fluorescein-isothiocyanate (FITC), CD23-FITC, FMC7- phycoerythrin (PE), CD79-PE (Beckman Coulter). Dual staining was performed for CD5-FITC/CD19-PE, Kappa-FITC/Lambda-PE, CD19-PE/CD38-FITC and CD19PE/ZAP-70-FITC (DAKO) to determine cytoplasmic ZAP-70 expression according to the manufacturer's instructions. A cut-off point of $20 \%$ was used to define positivity for CD38 and ZAP-70.

\section{Serum IL-9 measurement:-}

Serum samples from 80 CLL patients and 80 healthy volunteers were collected and frozen at $-80^{\circ} \mathrm{C}$. IL-9 levels in sera were quantified using human ELISA kit (Affymetrix, eBioscience) according to the manufacturer's instructions. The sensitivity limit for quantitative determination was $1 \mathrm{pg} / \mathrm{ml}$. 


\section{IL9 gene expression:-}

Purification of total cellular RNA from human whole blood was done using QIAamp ${ }^{\circledR}$ RNA blood Mini kit (Qiagen, USA). The concentration and purity of RNA were measured at 260, 280 and $230 \mathrm{~nm}$ using Nanodrop2000 spectrophotometer (Thermo Scientific, USA). A260:A230 ratio greater than 1.7 and A260:A280 ratio greater than 2.0 indicates highly pure RNA. A reverse transcriptase kit (QuantiTect reverse transcription kit, Qiagen, USA) was used for complementary DNA (cDNA) synthesis according to the manufacturer's instructions.

The expression of IL-9 mRNA was analysed with the ready to use QuantiFast ${ }^{\circledR}$ probe two-step real-time RT-PCR assay (Qiagen, USA). Expression data were normalized to the geometric mean of the housekeeping gene Glyceraldehyde-3-phosphate dehydrogenase (GAPDH) to control the variability in expression levels by RT-PCR, using real-time cycler Rotor gene $Q^{\circledR}$ (Qiagen, USA). Data analysis was done using the $2^{\wedge}{ }^{\wedge \Delta C T}$ method.

\section{Statistical analysis:-}

Data were fed to the computer and analyzed using IBM SPSS software package version 20.0 (SPSS Inc., Chicago, IL, USA). Comparisons between groups for categorical variables were assessed using Chi-square test $\left(\chi^{2}\right)$. Student ttest was used to compare two groups for normally distributed quantitative variables. Mann-Whitney test was used to compare two groups for abnormally distributed quantitative variables. Spearman coefficient was used to correlate between quantitative variables. Significance of the obtained results was judged at the 5\% level.

\section{Results:-}

\section{Serum IL-9 in CLL patients:-}

Serum levels of IL-9 were measured in CLL patients and healthy controls using ELISA to investigate the possible involvement of IL-9 in CLL as illustrated in figure (1). The data showed that serum IL-9 levels in CLL patients were significantly higher than in healthy controls $(\mathrm{P}<0.001)$.

\section{IL-9 mRNA expression in CLL patients:-}

Using an RT-PCR approach, we detected the expression levels of IL-9 mRNA in CLL patients as shown in figure (2). A significantly higher expression of IL-9 mRNA was found in CLL patients than in healthy controls $(\mathrm{P}<0.001)$.

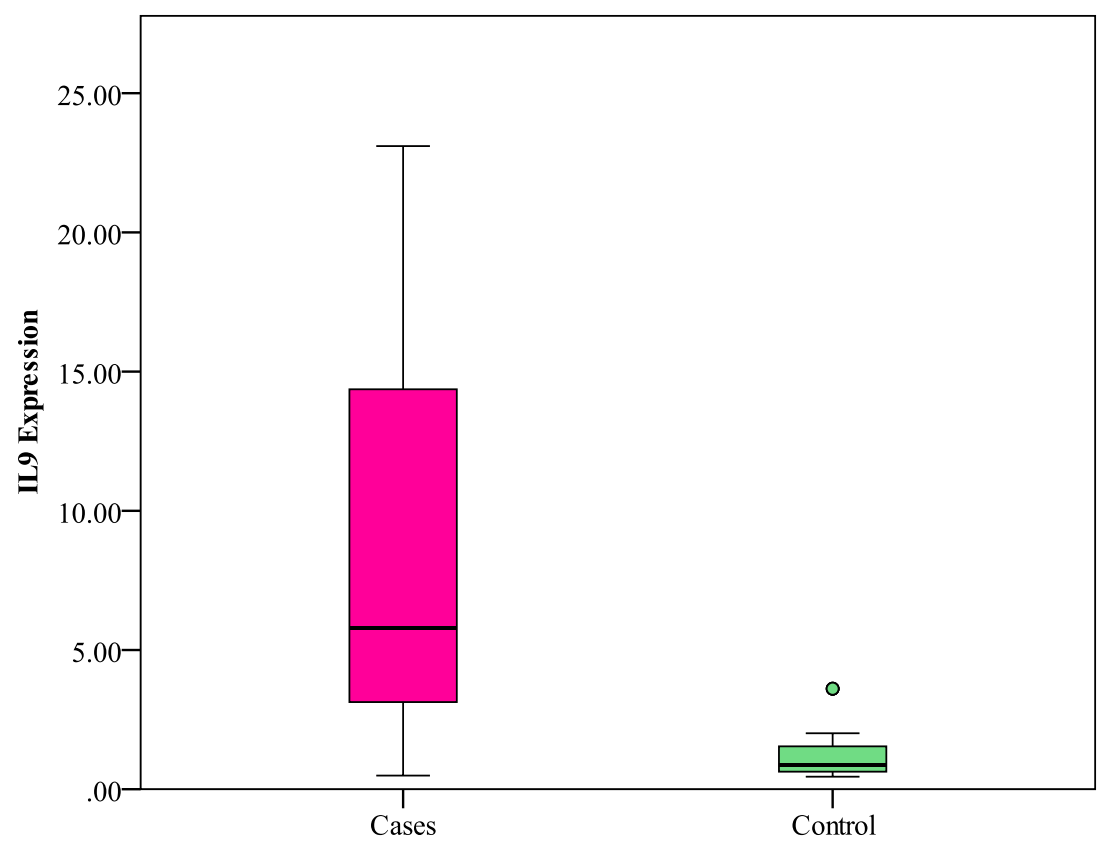

Figure 1:- Comparison between the two studied groups as regards IL9 Expression 


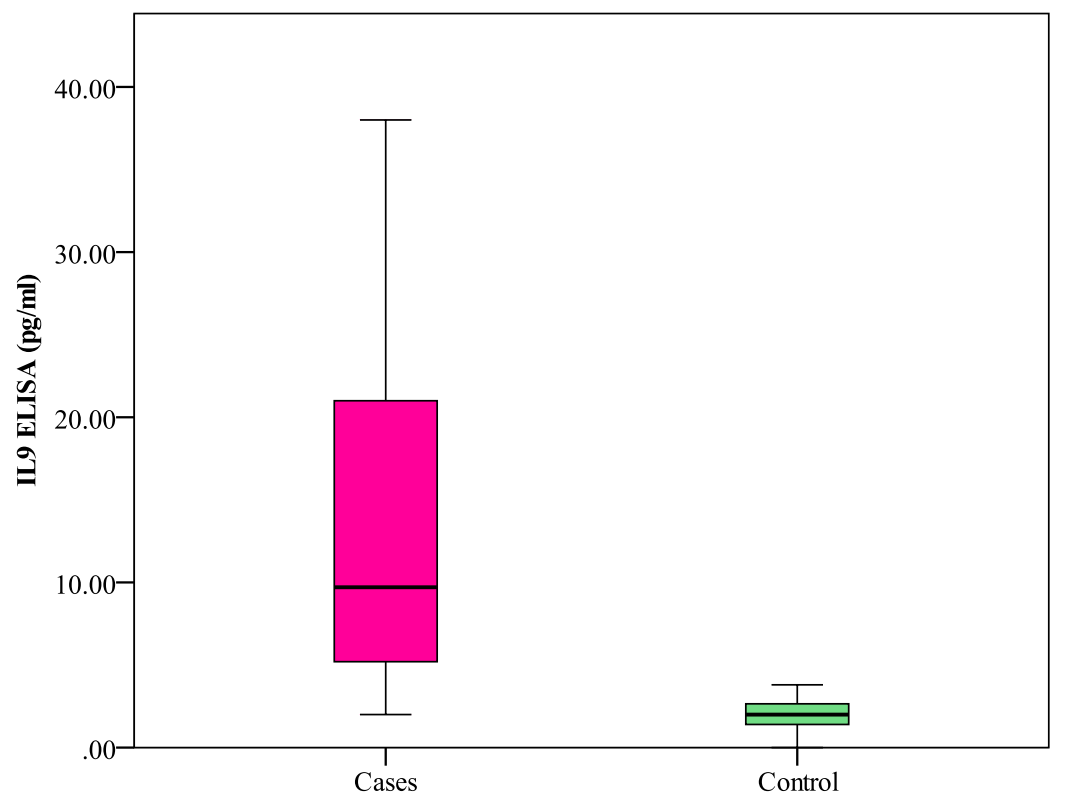

Figure 2:- Comparison between the two studied groups as regards serum IL9 (pg/ml) by ELISA

\section{Expression of IL-9 and association with other prognostic factors:-}

In a total of 80 CLL cases, no association was found between serum IL-9 or its expression level and patient age $(\mathrm{P}=0.488)$, nor gender $(\mathrm{P}=0.952, \mathrm{P}=1.000)$ respectively. The possibility of interaction between IL-9 and other known prognostic factors was analyzed in our cohort as presented in table (1). Modified Rai staging was strongly associated with both a significantly higher level of IL-9 in serum as well as a significant overexpression of IL-9 ( $<<0.001)$. Similarly, the expression and serum levels of IL-9 were strongly correlated to ZAP-70 and CD 38 expression $(\mathrm{P}<0.001)$. These results indicated that the overexpression of IL-9 was associated with CLL clinical progression.

\section{Correlation between serum IL-9 and IL-9 mRNA expression:-}

As shown in table (2), a significant negative correlation was found between serum IL-9 and its expression level with hemoglobin concentration ( $\mathrm{Rs}=-0.454$, Rs $=-0.468)$ respectively. Likewise, they showed a significant negative correlation with platelet count (Rs= -0.339 , Rs $=-0.353$ ) respectively. On the other hand, serum IL-9 and its mRNA expression had a significant positive association with $\mathrm{WBC}$ count $(\mathrm{Rs}=0.453$, Rs $=0.441)$ respectively. Moreover, significant positive correlations were marked between IL-9 overexpression and its serum levels with other prognostic factors as ZAP-70 expression $(\mathrm{Rs}=0.604$, $\mathrm{Rs}=0.580)$ respectively, as well as, CD 38 expression (Rs= $0.684, \mathrm{Rs}=0.697$ ) respectively.

Table 1:- Relation between IL9 Expression and IL9 ELISA with the different parameters in patients with CLL

\begin{tabular}{|c|c|c|c|c|c|c|}
\hline & \multicolumn{3}{|c|}{ IL9 Expression } & \multicolumn{3}{|c|}{ Serum IL9 (pg/ml) } \\
\hline & Median & (Min. -Max.) & $\mathbf{p}$ & Median & (Min. - Max.) & $\mathbf{p}$ \\
\hline \multicolumn{7}{|l|}{ Age } \\
\hline$<60$ & 5.81 & $0.74-23.10$ & \multirow[t]{2}{*}{0.488} & 9.70 & $2.30-38.0$ & \multirow[t]{2}{*}{0.488} \\
\hline$\geq 60$ & 5.31 & $0.49-18.24$ & & 9.0 & $2.0-30.0$ & \\
\hline \multicolumn{7}{|l|}{ Sex } \\
\hline Male & 5.79 & $0.49-23.10$ & \multirow[t]{2}{*}{1.000} & 9.70 & $2.0-38.0$ & \multirow[t]{2}{*}{0.952} \\
\hline Female & 5.34 & $0.55-18.24$ & & 9.40 & $2.0-30.0$ & \\
\hline \multicolumn{7}{|l|}{$\mathbf{L N}$} \\
\hline No & 5.35 & $4.44-23.10$ & \multirow[t]{6}{*}{$0.007^{*}$} & 8.0 & $6.0-38.0$ & \multirow[t]{6}{*}{0.008} \\
\hline Generalized & 6.50 & $0.55-19.70$ & & 12.0 & $2.0-30.0$ & \\
\hline Submandibular, inguinal & 2.41 & $2.41-2.41$ & & 4.20 & $4.20-4.20$ & \\
\hline Cervical & 1.97 & $0.49-3.19$ & & 3.90 & $2.0-5.50$ & \\
\hline Cervical, axillary & 4.44 & $0.70-18.24$ & & 5.0 & $3.0-30.0$ & \\
\hline Axillary, Paraaortic & 11.68 & $11.68-11.68$ & & 13.0 & $13.0-13.0$ & \\
\hline
\end{tabular}




\begin{tabular}{|c|c|c|c|c|c|c|}
\hline Splenomegaly & & & & & & \\
\hline No & 4.46 & $0.70-11.68$ & \multirow[t]{2}{*}{$0.001^{*}$} & 7.45 & $2.30-13.0$ & \multirow[t]{2}{*}{$<0.001^{*}$} \\
\hline Splenomegaly & 13.70 & $0.49-23.10$ & & 17.50 & $2.0-38.0$ & \\
\hline \multicolumn{7}{|l|}{ Hepatomegaly } \\
\hline No & 4.99 & $0.49-23.10$ & \multirow[t]{2}{*}{0.059} & 8.0 & $2.0-38.0$ & \multirow[t]{2}{*}{0.062} \\
\hline Hepatomegaly & 13.70 & $2.15-17.88$ & & 17.50 & $3.70-30.0$ & \\
\hline \multicolumn{7}{|l|}{ Modified Rai Stage } \\
\hline Low & 4.44 & $0.70-11.68$ & \multirow[t]{3}{*}{$<0.001^{*}$} & 5.75 & $2.30-13.0$ & \multirow[t]{3}{*}{$<0.001^{*}$} \\
\hline Intermediate & 4.56 & $0.49-18.24$ & & 8.0 & $2.0-30.0$ & \\
\hline High & 15.68 & $4.17-23.10$ & & 25.0 & $7.0-38.0$ & \\
\hline \multicolumn{7}{|l|}{ Zap70\% } \\
\hline$<20$ (Negative) & 4.44 & $0.49-17.36$ & \multirow[t]{2}{*}{$<0.001^{*}$} & 6.0 & $2.0-30.0$ & \multirow[t]{2}{*}{$<0.001^{*}$} \\
\hline$\geq 20$ (Positive) & 15.68 & $5.35-23.10$ & & 25.0 & $8.0-38.0$ & \\
\hline \multicolumn{7}{|l|}{ CD38\% } \\
\hline$<20$ (Negative) & 4.44 & $0.49-15.68$ & \multirow[t]{2}{*}{$<0.001^{*}$} & 5.75 & $2.0-26.20$ & \multirow[t]{2}{*}{$<0.001^{*}$} \\
\hline$\geq 20$ (Positive) & 16.40 & $4.17-23.10$ & & 27.0 & $7.0-38.0$ & \\
\hline
\end{tabular}

Abnormally distributed data were expressed in median (Min. - Max.) and were compared using Mann Whitney test

*: Statistically significant at $\mathrm{p} \leq 0.05$

Table 2:- Correlation between IL9 Expression and IL9 ELISA with different parameters in patients with CLL

\begin{tabular}{|l|l|l|l|l|}
\hline & \multicolumn{2}{l|}{ IL9 Expression } & IL9 ELISA pg/ml \\
\hline & $\mathrm{r}_{\mathrm{s}}$ & $\mathrm{p}$ & $\mathrm{r}_{\mathrm{s}}$ & $\mathrm{p}$ \\
\hline HB & $-0.468^{*}$ & $<0.001$ & $-0.454^{*}$ & $<0.001$ \\
\hline WBCs & $0.441^{*}$ & $<0.001$ & $0.453^{*}$ & $<0.001$ \\
\hline Platelets & $-0.339^{*}$ & 0.002 & $-0.353^{*}$ & 0.001 \\
\hline Zap70\% & $0.604^{*}$ & $<0.001$ & $0.580^{*}$ & $<0.001$ \\
\hline CD38\% & $0.684^{*}$ & $<0.001$ & $0.697^{*}$ & $<0.001$ \\
\hline
\end{tabular}

$\mathrm{r}_{\mathrm{s}}$ : Spearman coefficient

*: Statistically significant at $\mathrm{p} \leq 0.05$

\section{Discussion:-}

A series of observations have pointed to IL-9 as a factor promoting oncogenesis, especially lymphomagenesis [17]. IL-9 is able to stimulate proliferation of lymphoma cells [18] and protect them from dexamethasone (DEX)-induced apoptosis [19]. Extensive studies have confirmed the oncogenic activities of IL-9 in lymphoma.

In the current study, serum IL-9 levels in patients with CLL were significantly higher than in healthy controls. Furthermore, a significantly higher expression of IL-9 mRNA was found in those patients. Likewise, an elevated serum level of IL-9 was found in B-cell NHL patients through immunosuppression up-regulation which is mediated by Treg cells and mast cells [20]. It was markedly overexpressed in diffuse large B-cell lymphoma DLBCL tissues in comparison to their counterparts, and it was associated with several adverse prognostic parameters. [21].

In the present study, modified Rai staging was strongly associated with both a significantly higher level of IL-9 in serum as well as a significant overexpression of its mRNA. A novel correlation was found between increased serum IL-9 levels, Hodgkin lymphoma and clinical features [22]. Moreover, IL-9 overexpression was reported to be strongly correlated to the clinical staging of patients with CLL [16]. Additionally, it was reported that IL-9 was constitutively expressed in human T-cell leukemia virus-I-transformed human $\mathrm{T}$ cells, assuming a possible correlation between IL-9 expression and T cell lymphoma/leukemia [23]. Similarly, the expression and serum levels of IL-9, in the current study, were strongly correlated to ZAP-70 and CD 38 expression. These results identified that the elevated levels of expression of IL-9 was associated with CLL clinical progression. Higher ZAP-70 expression was reported to predict cases with unfavorable clinical courses as regards disease progression and overall survival OS [24]. In fact, ZAP-70 protein expression in CLL patients seems to have more predictive value than IGHV mutations, with a constant expression level during the course of disease [25]. The majority of mutated cases were reported to be ZAP-70-negative, whereas unmutated forms were ZAP-70-positive and patients with mutated IGHV genes had significantly better survival compared with patients with unmutated IGHV genes [26]. Nevertheless, CD38 is also an evident adverse prognostic marker for patients with CLL. CD $38^{+}$CLL cells are 
characterized by a marked proliferative potential and by decreased sensitivity to chemotherapies [27]. Hence, the expression intensity of IL-9 is correlated with other known adverse prognostic indicators of CLL.

In addition, a significant negative correlation was found between serum IL-9 and its expression level with hemoglobin concentration as well as the platelet count. Meanwhile, serum IL-9 and its mRNA expression had a significant positive association with WBC count, with more advanced Rai stages, with large intrathoracic/abdominal lymphadenopathies and splenomegaly, all hallmarks of an active and aggressive disease. The association between IL-9 upregulation and patient characteristics provided direct clinical evidence for the contribution of IL-9 to the pathogenesis of CLL.

In conclusion, significantly higher expression of IL -9 measured at both the mRNA and the protein levels in patients with CLL that correlates with more complex course of the disease and worse prognosis may allow one to speculate its importance in the pathogenesis of the disease and its possible impact on prognosis.

\section{The authors declare that they have no conflict of interest.}

\section{Acknowledgements:-}

No funds were available for this study.

\section{References:-}

1. Chiorazzi N, Rai KR, Ferrarini M. Chronic lymphocytic leukemia. N Engl J Med.2005; 352(8):804-15.

2. Zenz T, Mertens D, Kuppers R, Döhner H, Stilgenbauer S. From pathogenesis to treatment of chronic lymphocytic leukaemia. Nat Rev Cancer.2010; $10: 37-50$.

3. Moussay E, Wang K, Cho JH, van Moer K, Pierson S, Paggetti J, Nazarov PV, Palissot V, Hood LE, Berchem $\mathrm{G}$, Galas DJ. MicroRNA as biomarkers and regulators in B-cell chronic lymphocytic leukemia. Proc Natl Acad Sci USA. 2011;108:6573-8

4. Corcoran M, Parker A, Orchard J, Davis Z, Wirtz M, Schmitz OJ, Oscier D. ZAP-70 methylation status is associated with ZAP-70 expression status in chronic lymphocytic leukemia. Haematologica.2005; 90:1078-88.

5. Dürig J, Naschar M, Schmücker U, Renzing-Köhler K, Hölter T, Hüttmann A, Dührsen U. CD38 expression is an important prognostic marker in chronic lymphocytic leukaemia. Leukemia. 2002;16:30-35.

6. Van Bockstaele F, Pede V, Janssens A, Callewaert F, Offner F, Verhasselt B, Philippe J. Lipoprotein lipase mRNA expression in whole blood is a prognostic marker in B cell chronic lymphocytic leukemia. Clin Chem.2007;53:204-12.

7. Zhu P, Degheidy HA, Marti GE, Li S, Abbasi F, Wiestner A, Amstutz P, Tang CM. Quantitative detection of zeta-chain-associated protein 70 expression in chronic lymphocytic leukemia. Leukemia lymphoma. 2013; 54(3):579-86.

8. Ritgen M, Lange A, Stilgenbauer S, Döhner H, Bretscher C, Bosse H, Stuhr A, Kneba M, Dreger P. Unmutated immunoglobulin variable heavy-chain gene status remains an adverse prognostic factor after autologous stem cell transplantation for chronic lymphocytic leukemia. Blood. 2003; 101: 2049-53

9. Krober A, Seiler T, Benner A, Bullinger L, Brückle E, Lichter P, Döhner H, Stilgenbauer S. V(H) mutation status, CD38 expression level, genomic aberrations, and survival in chronic lymphocytic leukemia. Blood.2002;100: $1410-6$

10. Demoulin J-B, Renauld J-C. Interleukin 9 and its receptor: an overview of structure and function. Int. Rev. Immunol. 1998; 16: 345-64

11. Richard M, Grencis RK, Humphreys NE, Renauld J-C, Van Snick J. Anti-IL-9 vaccination prevents worm expulsion and blood eosinophilia in Trichuris muris-infected mice. Proc. Natl. Acad. Sci. 2000; 97: 767-72.

12. Hornakova T, Staerk J, Royer Y, Flex E, Tartaglia M, Constantinescu SN, Knoops L, Renauld JC. Acute lymphoblastic leukemia-associated JAK1 mutants activate the Janus kinase/STAT pathway via interleukin-9 receptor alpha homodimers. J Biol Chem.2009; 284:6773-81.

13. Shang Y, Kakinuma S, Amasaki Y, Nishimura M, Kobayashi Y, Shimada Y. Aberrant activation of interleukin9 receptor and downstream Stat3/5 in primary T-cell lymphomas in vivo in susceptible B6 and resistant $\mathrm{C} 3 \mathrm{H}$ mice. In Vivo.2008;22: 713- 20.

14. Renauld JC, Druez C, Kermouni A, Houssiau F, Uyttenhove C, Van Roost E, Van Snick J. Expression cloning of the murine and human interleukin 9 receptor cDNAs. Proc Natl Acad Sci 1992; 89:5690-4.

15. Kumar V. Innate lymphoid cells: new paradigm in immunology of inflammation. Immunol Lett. 2014; 157:2337. 
16. Chen N, Lv X, Li P, Lu K, Wang X. Role of high expression of IL-9 in prognosis of CLL. Int J Clin Exp Pathol. 2014;7: 716-21.

17. Bittner C, Merz H, Krokowski M, Briese J, Wiedemann GJ, Feller AC. New immunotherapeutic approaches for the treatment of anaplastic large cell lymphoma in a mouse model. Verh Dtsch Ges Pathol. 2000;84:187-98.

18. Jaffe ES, Harris NL, Stein H, Isaacson PG. Classification of lymphoid neoplasms: the microscope as a tool for disease discovery. Blood. 2008;112:4384-99.

19. Qiu L, Lai R, Lin Q, Lau E, Thomazy DM, Calame D, Ford RJ, Kwak LW, Kirken RA, Amin HM. Autocrine release of interleukin-9 promotes Jak3-dependent survival of ALK+ anaplastic large-cell lymphoma cells. Blood. 2006;108:2407-15.

20. Feng LL, Gao JM, Li PP, Wang X. IL-9 contributes to immunosuppression mediated by regulatory T cells and mast cells in B-cell non-Hodgkin's lymphoma. J Clin Immunol.2011;31:1084-94.

21. Lv X, Feng L, Fang X, Jiang Y, Wang X. Overexpression of IL-9 receptor in diffuse large B-cell lymphoma. Int J Clin Exp Pathol. 2013;6:911-6.

22. Fischer M, Bijman M, Molin D, Cormont F, Uyttenhove C, van Snick J, Sundström C, Enblad G, Nilsson G. Increased serum levels of interleukin-9 correlate to negative prognostic factors in Hodgkin's lymphoma. Leukemia2003; 17: 2513-6

23. Kelleher K, Bean K, Clark SC, Leung WY, Yang-Feng TL, Chen JW, Lin PF, Luo W, Yang YC. Human interleukin-9: genomic sequence, chromosomal location, and sequences essential for its expression in human Tcell leukemia virus (HTLV)-Itransformed human T cells. Blood 1991; 77: 1436-41.

24. Orchard JA, Ibbotson RE, Davis Z. Wiestner A, Rosenwald A, Thomas PW, Hamblin TJ, Staudt LM, Oscier DG. ZAP-70 expression and prognosis in chronic lymphocytic leukaemia. Lancet. 2004; 363: 105-11

25. Rassenti LZ, Huynh L, Toy TL, Chen L, Keating MJ, Gribben JG, Neuberg DS, Flinn IW, Raj KR, Byrd JC, Kay NE, Greaves A, Weiss A, Kipps TJ. ZAP-70 compared with immunoglobulin heavy-chain gene mutation status as a predictor of disease progression in chronic lymphocytic leukemia. N Engl J Med.2004; 351: 893901

26. Damle RN, Wasil T, Fais F, Ghiotto F, Valetto A, Allen SL, Buchbinder A, Budman D, Dittmar K, Kolitz J, Lichtman SM, Schulman P, Vinciguerra VP, Raj KR, Ferrarini M, Chiorazzi N. Ig V gene mutation status and CD38 expression as novel prognostic indicators in chronic lymphocytic leukemia. Blood.1999;94:1840-7.

27. Matrai Z. CD38 as a prognostic marker in CLL. Hematology 2005;10: 39-46. 